\title{
Competition between core and periphery-based processes in warm convective clouds - from invigoration to suppression
}

\author{
G. Dagan, I. Koren, and O. Altaratz \\ Department of Earth and Planetary Sciences, The Weizmann Institute, Rehovot 76100, Israel \\ Correspondence to: I. Koren (ilan.koren@weizmann.ac.il)
}

Received: 17 August 2014 - Published in Atmos. Chem. Phys. Discuss.: 12 September 2014

Revised: 2 February 2015 - Accepted: 20 February 2015 - Published: 10 March 2015

\begin{abstract}
How do changes in the amount and properties of aerosol affect warm clouds? Recent studies suggest that they have opposing effects. Some suggest that an increase in aerosol loading leads to enhanced evaporation and therefore smaller clouds, whereas other studies suggest clouds' invigoration. In this study, using an axisymmetric bin-microphysics cloud model, we propose a theoretical scheme that analyzes the evolution of key processes in warm clouds, under different aerosol loading and environmental conditions, to explain this contradiction.

Such an analysis of the key processes reveals a robust reversal in the trend of the clouds' response to an increase in aerosol loading. When aerosol conditions are shifted from superpristine to slightly polluted, the clouds formed are deeper and have larger water mass. Such a trend continues up to an optimal concentration $\left(N_{\text {op }}\right)$ that allows the cloud to achieve a maximal water mass. Hence, for any concentration below $N_{\text {op }}$ the cloud formed contains less mass and therefore can be considered as aerosol-limited, whereas for concentrations greater than $N_{\text {op }}$ cloud periphery processes, such as enhanced entrainment and evaporation, take over leading to cloud suppression. We show that $N_{\text {op }}$ is a function of the thermodynamic conditions (temperature and humidity profiles). Thus, profiles that favor deeper clouds would dictate larger values of $N_{\text {op }}$, whereas for profiles of shallow convective clouds, $N_{\text {op }}$ corresponds to the pristine range of the aerosol loading.

Such a view of a trend reversal, marked by the optimal concentration, $N_{\text {op }}$, helps one to bridge the gap between the contradictory results of numerical models and observations. Satellite studies are biased in favor of larger clouds that are characterized by larger $N_{\text {op }}$ values and therefore invigoration is observed. On the other hand, modeling studies of cloud
\end{abstract}

fields are biased in favor of small, mostly trade-like convective clouds, which are characterized by low $N_{\text {op }}$ values (in the pristine range) and, therefore, cloud suppression is mostly reported as a response to an increase in aerosol loading.

\section{Introduction}

Clouds play an important role in Earth's energy balance (Baker and Peter, 2008) and the hydrological cycle. The clouds' macrophysical properties, such as coverage and the vertical extent as well as microphysical properties like liquid water content (LWC), particle size, shape, and phase, determine the cloud's interaction with electromagnetic radiation. Because of the inherent variance in cloud types and properties and the complexity of the processes, clouds are responsible for the greatest uncertainty in climate research (Forster et al., 2007; Boucher et al., 2013). To better understand the role of clouds in the current climate system and to be able to predict their properties under different climate change scenarios, we must advance our understanding of those processes and environmental factors that affect cloud properties.

Aerosols act as cloud condensation nuclei $(\mathrm{CCN})$, on which droplets can form, and as ice nuclei (IN) for the initial creation of ice particles. A theoretically clean atmosphere with no aerosols is suggested to be mostly cloud free (Reutter et al., 2009; Koren et al., 2014). CCN enable the nucleation of droplets by reducing the supersaturation required for the process. Without CCN, droplets would form at supersaturation levels of several hundred percent by homogenous nucleation. However, in the presence of CCN, droplets are formed by a heterogeneous nucleation process, which requires an order of $1 \%$ supersaturation (Wilson, 1897; Prup- 
pacher and Klett, 1978). The availability, size distribution, and chemical properties of aerosols govern the initial number and size distribution of the droplets. Polluted clouds initially have smaller and more numerous droplets with narrower size distribution (Squires, 1958; Squires and Twomey, 1960; Warner and Twomey, 1967; Fitzgerald and SpyersDuran, 1973; Twomey, 1977).

The change in the initial droplet size distribution (due to changes in the aerosol number concentration) affects key processes and the interactions between those processes. For a given total liquid water mass (or volume), the total surface area of smaller droplets is larger and, therefore, the condensation process is more efficient under the given supersaturation conditions (consuming the supersaturation in a shorter timescale) (Pinsky et al., 2013; Seiki and Nakajima, 2014). On the other hand, similarly, under subsaturation conditions (characteristic for cloud periphery), smaller droplets evaporate more efficiently and may enhance the mixing processes between the cloud and the drier surrounding air due to the evaporative cooling-induced downdrafts (Xue and Feingold, 2006; Jiang et al., 2006; Small et al., 2009). These two processes create an interesting competition controlled by the relative humidity $(\mathrm{RH})$ conditions in different regions of the clouds and in its surroundings. The collision-coalescence and rain processes are impacted by the change in the droplets' size distribution (caused by the changes in the aerosol number concentration) as well. There is a delay in the initiation of the collision-coalescence process in polluted clouds (Gunn and Phillips, 1957; Squires, 1958; Warner, 1968; Albrecht, 1989). These microphysical processes were suggested to be coupled to dynamical ones and in the case of convective clouds to form the baseline for the invigoration effect in which high aerosol loading leads to larger and deeper clouds with larger water mass (Andreae et al., 2004; Koren et al., 2005; Rosenfeld et al., 2008; Tao et al., 2012; Fan et al., 2013). Surface rain, as the end result of all the cloud's feedbacks, was shown to be affected by changes in aerosol loading as well (Levin and Cotton, 2009; Khain, 2009; Koren et al., 2012).

Unlike the straightforward physical basis of the Twomey effect, in which for a given amount of LWC an increase in the aerosol loading increases the amount of cloud droplets and therefore reduces the droplets' average size (and increases the cloud's reflectivity; Twomey, 1977). Invigoration is the outcome of a series of feedbacks that are all a result of the aerosol-imposed changes on the droplets' initial size distribution (Altaratz et al., 2014). As such, the invigoration effect can be expressed in several different forms such as an increase in the cloud's total mass, or an increase in the cloud's depth and area (Koren et al., 2005; Rosenfeld et al., 2008; Tao et al., 2012). In this work we use the cloud's total mass as the main measure for cloud invigoration.

Currently, although some of the key elements that lead to invigoration such as increased condensation efficiency, changes in fall velocity and delay in the onset of the collec- tion process (Pinsky et al., 2013; Seiki and Nakajima, 2014; Koren et al., 2014; Rosenfeld et al., 2013; Khain, 2009) do play an important role in warm convective clouds (containing only liquid water drops), the overall effect of the addition of aerosols on the clouds' macrophysical properties is still considered an open question and there is contradictory evidence. There are few observational studies that show cloud invigoration by aerosols. Kaufman et al. (2005) found an increase in cloud coverage under polluted, smoky, and dusty conditions over the transition zone between stratocumulus and cumulus clouds over the tropical Atlantic Ocean. Yuan et al. (2011) showed a larger coverage of trade cumulus clouds and higher cloud top associated with volcanic aerosols near Hawaii. Dey et al. (2011) showed that over the Indian Ocean cloud fraction increases with the increase in aerosol optical depth while changing from clean to slightly polluted conditions, and is then followed by a decrease in cloud fraction for higher pollution levels. Those observations were explained by the semi-direct effect (absorbing aerosols) that stabilizes the lower atmosphere. Costantino and Bréon (2013) studied warm clouds over the southeastern Atlantic and found a higher cloud fraction for increased aerosol loading. Koren et al. (2014) have recently made the link between the concept of "aerosol-limited clouds" and invigoration. They showed that warm convective clouds over the Southern Oceans can be considered as "aerosol-limited" up to moderate aerosol loading conditions and therefore an increase in the aerosol loading from pristine to slightly polluted drives deeper clouds with larger areas (i.e., invigorated clouds). On the other hand, some observational studies like that of Li et al. (2011), who studied warm clouds over the southern great plains of the United States, reported that aerosol did not affect the clouds' top height.

Numerical studies of an aerosol's effect on warm cumulus clouds show either no effect or, in contrast with invigoration, they show suppression. Jiang and Feingold (2006) found that an increase in aerosol loading in fields of warm shallow convective clouds results in reduced precipitation. However, the clouds do not undergo significant changes in LWP (liquid water path), cloud fraction, and cloud depth. Xue et al. (2008) found that the addition of aerosols leads to smaller clouds and suppression of precipitation. Jiang et al. (2010) found a monotonic decrease in precipitation with the increase in aerosol loading. They demonstrated a non-monotonic change in the derivative of the surface rain rate with aerosol loading (determined as susceptibility) for clouds with a higher maximal liquid water path. Seigel (2014) showed that under polluted conditions cloud and cloud-core sizes decrease. The shrinking of the polluted clouds was explained by enhanced entrainment-driven evaporation at the cloud margins. He also showed that the clouds' core vertical velocity is higher under polluted conditions.

The sensitivity of deep convective clouds and precipitation to aerosol properties were shown to depend on the envi- 
Table 1. A summary of the notations, inversion base height and RH levels in the cloudy layer for the nine different initial atmospheric profiles. The temperature at the inversion is presented in the bottom row. For each profile 10 simulations were run with aerosol concentrations of 5 , $25,125,250,500,1000,2000,3000,4000$ and $10000 \mathrm{~cm}^{-3}$.

\begin{tabular}{llll}
\hline & T1 & T2 & T3 \\
\hline RH1 & T1RH1: $4 \mathrm{~km}, 95 \%$ & T2RH1: $3 \mathrm{~km}, 95 \%$ & $\mathrm{~T} 3 \mathrm{RH} 1: 2 \mathrm{~km}, 95 \%$ \\
RH2 & $\mathrm{T} 1 \mathrm{RH} 2: 4 \mathrm{~km}, 90 \%$ & $\mathrm{~T} 2 \mathrm{RH} 2: 3 \mathrm{~km}, 90 \%$ & $\mathrm{~T} 3 \mathrm{RH} 2: 2 \mathrm{~km}, 90 \%$ \\
$\mathrm{RH} 3$ & $\mathrm{~T} 1 \mathrm{RH} 3: 4 \mathrm{~km}, 80 \%$ & $\mathrm{~T} 2 \mathrm{RH} 3: 3 \mathrm{~km}, 80 \%$ & $\mathrm{~T} 3 \mathrm{RH} 3: 2 \mathrm{~km}, 80 \%$ \\
\hline $\begin{array}{l}\text { Inversion } \\
\text { temperature }\end{array}$ & $-0.8^{\circ} \mathrm{C}$ & $6.0^{\circ} \mathrm{C}$ & $12.2^{\circ} \mathrm{C}$ \\
\hline
\end{tabular}

ronmental condition (Seifert and Beheng, 2006; Khain et al., 2008; Lee et al., 2008; Fan et al., 2009).

Seifert and Beheng (2006) studied the role of vertical wind shear and the convective available potential energy (CAPE) in modulating the clouds' maximum vertical velocity and the surface precipitation amount. For higher CAPE values and lower vertical wind shear conditions, higher aerosol loading resulted in clouds' invigoration. Low CAPE values and strong wind shear resulted in clouds suppression by aerosols. Fan et al. (2009) have shown that for deep convective clouds under strong wind shear conditions the increase in evaporative cooling due to the increase in aerosol loading is larger than the change in condensational heating and, thus, resulted in cloud suppression. Under weak wind shear and relatively clean conditions, the increase in condensational heating can be larger as aerosol loading increases, and leads to cloud invigoration. This trend continues up to an optimal aerosol concentration for which additional increase in aerosol loading can lead to cloud suppression.

Here we used a single cloud model to study how changes in aerosol loading affect warm convective clouds at the process level, with a dependency on the environmental conditions. More specifically, we describe the evolution in time and the competition between key processes: condensation/evaporation, collision-coalescence, rain fallout, drag force and entrainment. A single cloud model might be quite simplistic in capturing the dynamic processes on the whole cloud scale and does not account for larger (cloud-field scale) processes like self-organization and effects of clouds on the environmental conditions with time (Lee et al., 2014; Seifert and Heus, 2013). However, the essential microphysical and dynamical processes affecting finer scales are well captured and are the focus of this study.

\section{Methodology}

We used the Tel Aviv University axisymmetric (1.5-D) non-hydrostatic cloud model (TAU-CM) with a detailed treatment of cloud microphysics (Tzivion et al., 1994; Reisin et al., 1996). The warm microphysical processes included are nucleation of $\mathrm{CCN}$, condensation and evaporation, collision-coalescence, binary breakup (Low and List, 1982;
McTaggart-Cowan and List, 1975), and sedimentation. The microphysical processes are formulated and solved using a multimoment bin method (Tzivion et al., 1987). The model resolution was set to $50 \mathrm{~m}$ both in the vertical and horizontal directions, with a time step of $1 \mathrm{~s}$. An axisymmetric grid describes movement in the vertical and radial directions. It is limited in its ability to describe the dynamics.

To better understand the role of key environmental factors, we ran the model with nine different initial conditions based on idealized atmospheric profiles that characterize a moist tropical environment (Garstang and Betts, 1974). Each of the profiles includes a well-mixed subcloud layer between 0 and $\sim 1000 \mathrm{~m}$, a conditionally unstable cloud layer between 1000 and $4000 \mathrm{~m}$ (T1), $3000 \mathrm{~m}$ (T2), and $2000 \mathrm{~m}$ (T3), and an overlying inversion layer. We assigned three dew-point temperature profiles $\left(T_{\mathrm{d}}\right)$ equivalent to $95 \%$ relative humidity in the cloudy layer (RH1), $90 \%$ (RH2), and $80 \%$ (RH3) to each of the temperature (T1, T2, or T3) profiles (altogether nine profiles). The profiles are denoted here by a combination of the letters describing the temperature and humidity, such as T1RH1 or T1RH2 and so on. Table 1 summarizes the characteristics of the initialization profiles. The relative humidity above the inversion layer is $30 \%$ in all the profiles. The inversion layer has a temperature gradient of $2{ }^{\circ} \mathrm{C}$ over $50 \mathrm{~m}$. Figure 1 presents three of the initial profiles: T1 combined with RH1 (T1RH1), T2 with RH2 (T2RH2), and T3 with RH3 (T3RH3). The idealized profiles enable examination of the aerosol effect on warm convective clouds under a large range of environmental conditions (including very high $\mathrm{RH}$ values). It also minimizes the noise driven by local small-scale perturbations in the temperature and humidity profiles that usually appear in real sounding data. In the deepest cloud cases the cloud's top temperature is around $-10^{\circ} \mathrm{C}$; thus, there is a small likelihood that we neglect the formation of a thin mixed-phase layer. Because warm processes act as the initial and boundary conditions for mixedphase processes in deep convective clouds, extending the examination of warm convective clouds to the boundary between warm and mixed-phase clouds can improve the understanding of the effects of aerosol on deep convective clouds. For each initial atmospheric profile we ran the model with 10 different levels of aerosol concentrations, in the range of 


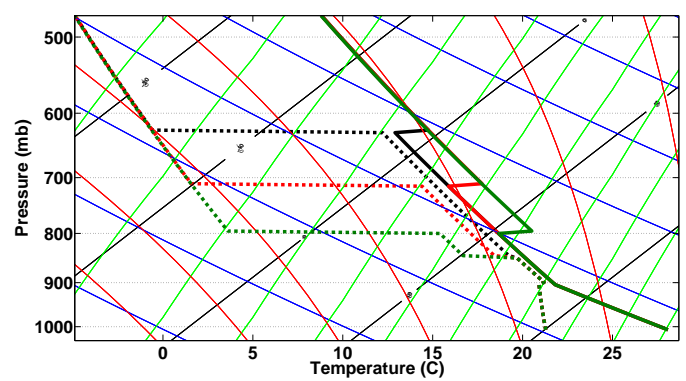

Figure 1. Thermodynamic diagram presenting examples of three of the initial atmospheric profiles; T1RH1 (black), T2RH2 (red), and T3RH3 (green). Solid lines denote temperature profiles and dashed lines dew-point temperature. In total, we ran simulations for nine different initialization profiles.

$5-10000 \mathrm{~cm}^{-3}$ (altogether 90 simulations). The background aerosol size distribution represents a maritime clean environment (Jaenicke, 1988; see Fig. S1 in the Supplement). The aerosols are assumed to be composed of $\mathrm{NaCl}$. In the clean cases $\left(5,25,125\right.$, and $\left.250 \mathrm{~cm}^{-3}\right)$ the basic marine size distribution $\left(\sim 290 \mathrm{~cm}^{-3}\right)$ was divided by a constant factor in order to obtain the requested concentration (while the shape of the size distribution was kept constant). In the polluted cases (500, 1000, 2000, 3000, 4000, and $10000 \mathrm{~cm}^{-3}$ ) we added to the background size distribution a lognormal distribution in sizes ranging from 0.012 to $0.844 \mu \mathrm{m}$ in order to represent anthropogenic pollution (a figure of the maritime background aerosol size distribution and two examples of polluted size distribution are given in the Supplement, Fig. S1). In this study, to reduce the complexity, we avoided the effect of giant CCN (GCCN; Feingold et al., 1999; Yin et al., 2000) by truncating the aerosol size distribution at $1 \mu \mathrm{m}$. The convection was initiated by a warm bubble of $3{ }^{\circ} \mathrm{C}$ at one grid point near the bottom of the domain.

The analysis of the effect of aerosol on convective clouds under different environmental conditions and understanding the role of key cloud processes requires simulation of many different clouds. Moreover, as we follow the time evolution of each process for each case, the size of the output data set of the runs becomes large. To reduce the dimensionality of the results of our 90 simulations and to distill the essence of the interplay between processes, we focused on the magnitude and timing of the key processes in the cloud's evolution like condensation/evaporation, collision-coalescence, rain fallout, drag force and entrainment.

\section{Results and discussion}

First we examined the bulk properties of clouds (on a whole cloud scale) of all the simulated clouds as a function of the aerosol loading.

Figure 2 presents the maximum cloud total mass with respect to the temporal evolution of each cloud as a function
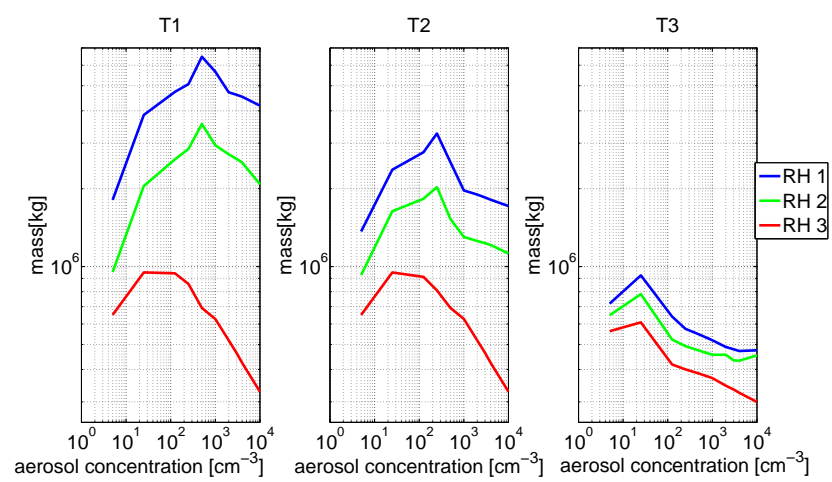

Figure 2. The maximum cloud total mass for each simulated cloud as a function of the aerosol concentration used in the simulation. Each curve represents 10 simulations conducted using the same atmospheric profile (a total of nine different initialization profiles). $\mathrm{T} 1$ represents a profile with an inversion layer located at $4 \mathrm{~km}, \mathrm{~T} 2$ at $3 \mathrm{~km}$, and T3 at $2 \mathrm{~km}$. RH1 represents a profile with $95 \% \mathrm{RH}$ in the cloudy layer, RH2 $90 \%$, and RH3 $80 \%$.
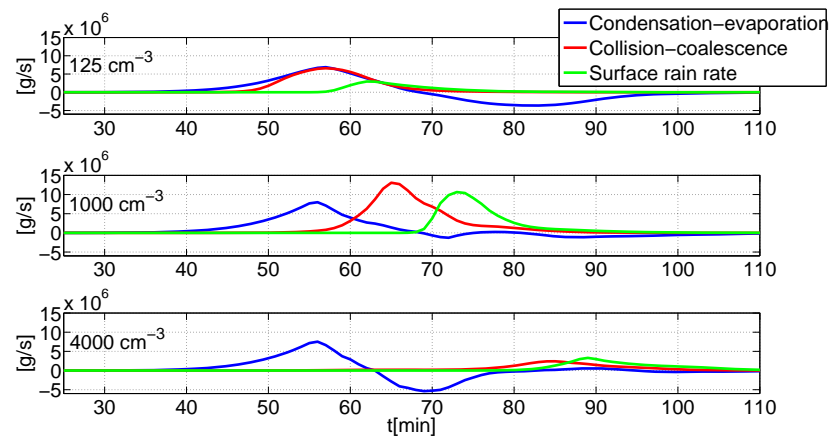

Figure 3. The total condensed-evaporated mass per unit time (blue), the total collected mass per unit time (red) and the surface rain mass (green) as a function of time for three clouds with aerosol levels of 125 (upper panel), 1000 (middle panel), and $4000 \mathrm{~cm}^{-3}$ (lower panel) of profile T1RH1.

of the aerosol concentration used for the same simulation. Each curve represents the results of 10 different simulations performed for each of the nine different initialization profiles (three profiles of temperature combined with three different levels of RH in the cloudy layer). In each of the curves (which represent 10 simulations done for different aerosol loading values, using one initialization profile) the maximum total cloud mass increases with the increase in aerosol loading until a maximum point. An additional increase in aerosol loading above this maximum value results in smaller maximal mass of the simulated clouds. We defined here the optimal aerosol concentration $\left(N_{\mathrm{op}}\right)$ as the concentration that is associated with the simulated cloud that has the largest maximum total liquid water mass per profile. In most cases, the $N_{\text {op }}$ value is larger for profiles characterized by a higher inversion base height and a higher RH value in the cloudy layer (a more humid environment). 

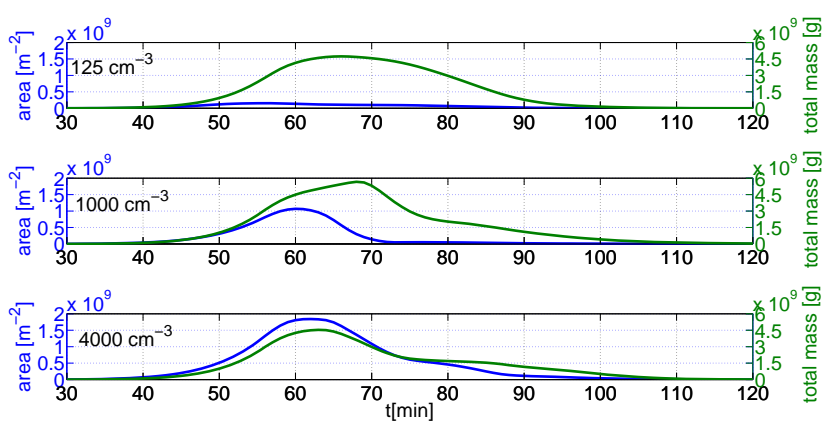

Figure 4. The total cloud water mass (green) and the total droplet surface area (blue) as a function of time for three clouds with aerosol levels of 125 (upper panel), 1000 (middle panel), and 4000 $\mathrm{cm}^{-3}$ (lower panel) for profile T1RH1.

The clouds' maximal total water mass, as presented in Fig. 2, represents the result of interactions of various clouds' internal processes that determine the clouds' properties at any given time. To understand the impact of aerosol on these processes and on the interactions between them, we followed the timing and magnitude of key microphysical processes in different clouds that were formed under the same environmental conditions (the same initialization profile) but with a different aerosol loading. Figures 3 and 4 present the results of three clouds that were formed under the conditions of profile T1RH1 with aerosol loading levels of 125,1000 , and $4000 \mathrm{~cm}^{-3}$ (denoted hereafter as T1RH1_125, T1RH1_1000, and T1RH1_4000). The results presented in Fig. 3 include the time evolution of three major cloud processes: diffusion (condensation-evaporation), collision-coalescence, and surface rain. The three curves represent (1) the total net condensed and evaporated mass in the cloud per unit time (the water vapor mass that was transferred to liquid; blue curves), (2) the total collected mass in the cloud per unit time (the mass transferred from small to bigger size bins; red curves), and (3) the surface rain mass per unit time (green curves). Figure 4 presents the time evolution of the total water mass and the total droplet surface area for those three clouds.

The differences in the magnitude and timing of the process among the three clouds, presented in Fig. 3, reveal an interesting interplay between processes. The total condensed mass along the whole lifetime of the cloud (summed over all grid points with supersaturation) is $1.25 \times 10^{8} \mathrm{~kg}$ in the clean cloud case (T1RH1_125), whereas it is $2.96 \times 10^{8} \mathrm{~kg}$ for the polluted cloud (T1RH1_4000). In agreement with previous studies (Reutter et al., 2009; Pinsky et al., 2013; Koren et al., 2014; Seiki and Nakajima, 2014; Khain et al., 2005), the differences in the total condensed mass are due to increased efficiency of the condensation process (consuming the supersaturation in shorter time) and the delay in the collisioncoalescence process, in the polluted cloud.
The condensation efficiency is determined by the droplets' surface area (Pinsky et al., 2013; Seiki and Nakajima, 2014) (Fig. 4). The total droplet surface area of cloud T1RH1_4000 at the time of its maximum total mass $\left(4.5 \times 10^{6} \mathrm{~kg}\right)$ is $1.8 \times 10^{9} \mathrm{~m}^{2}$, which yields a surface area-to-mass ratio of $406.7 \mathrm{~m}^{2} \mathrm{~kg}^{-1}$. For the clean cloud, T1RH1_125, the maximum total mass is $4.7 \times 10^{6} \mathrm{~kg}$, with a droplet surface area of $1.1 \times 10^{8} \mathrm{~m}^{2}$, which yields a surface area-to-mass ratio of $23.4 \mathrm{~m}^{2} \mathrm{~kg}^{-1}$. Therefore, the polluted cloud has a much higher droplet surface area per unit of water mass. This is maintained throughout the clouds' lifetime, with mean surface area-to-mass ratios of 77.8 and $357.6 \mathrm{~m}^{2} \mathrm{~kg}^{-1}$ for the clean and polluted clouds, respectively.

Moreover, the polluted cloud has a longer time for efficient condensational growth due to the delay in the initiation of the collision-coalescence. Whereas for the clean cloud case (T1RH1_125) the peaks of the collision-coalescence and condensation processes are at the same time (at $57 \mathrm{~min}$ of simulation), in the more polluted clouds the peak in the collision-coalescence process is delayed and appears after the peak in condensation $\left(9\right.$ min delay for the $1000 \mathrm{~cm}^{-3}$ case and $29 \mathrm{~min}$ for the $4000 \mathrm{~cm}^{-3}$ case). In all of these clouds the condensational growth stage ends more or less at the same time; however, in the clean clouds the collisioncoalescence becomes significant earlier, before the end of the condensational growth stage and, therefore, reduces the droplet surface area and the condensation efficiency. In the clean cloud case (T1RH1_125), the small number of droplets grows rapidly with almost no competition for the available water vapor. To demonstrate this point, we examined the early stages of the clouds' development. Five minutes after the clouds had formed, at the point of maximum liquid water content, cloud T1RH1_125 (T1RH1_4000) had a mean droplet radius of $7.3 \mu \mathrm{m}(2.4 \mu \mathrm{m})$ with a standard deviation of $2.3 \mu \mathrm{m}(0.4 \mu \mathrm{m})$.

The mean radius is larger and the size distribution is wider for the clean case; so, the droplets reach the critical size for collisions rapidly (Freud and Rosenfeld, 2012) and the collision-coalescence process becomes significant almost immediately after the start of condensation (Khain et al., 2005). The early initiation of the collision-coalescence process acts as a positive feedback for this aerosol effect on the condensed mass and further reduces the droplets' surface area (Fig. 4). The less effective condensation prevents the clean clouds from consuming more of the available supersaturation (Pinsky et al., 2013; Seiki and Nakajima, 2014). The condensation peaks at $57 \mathrm{~min}$ of simulation for the T1RH1_125 clean cloud (with $3.1 \%$ mean supersaturation in the supersaturated region in the cloud), compared with $56 \mathrm{~min}$ (with $0.02 \%$ mean supersaturation) in the T1RH1_4000 case. On the same note, the early initiation of the collision-coalescence process in the clean cloud also drives an early start of the rainout from the cloud. The early rainout leads to a downward mass transfer and therefore an increased drag force (which is proportional to the liquid wa- 
ter mass; Rogers and Yau, 1989) at the lower part of the cloud that further impedes the cloud's development (Khain et al., 2005). The clean cloud consumes a small amount of water vapor (a smaller total mass, as can be seen in Fig. 4) and rainout early (Fig. 3). On the other hand, the delay in the onset of the collision-coalescence process in the most polluted cloud (T1RH1_4000, see Fig. 3 lower panel) allows the entrainment to act for a longer time (after the peak in condensation) and, thus, enhances the evaporation; this, consequently, reduces the cloud's liquid water mass. The total evaporated mass along the entire lifetime of the cloud (integrated over all cloud grid points with subsaturation) in the clean cloud case (T1RH1_125) is $1.0 \times 10^{8} \mathrm{~kg}$, whereas it is $2.7 \times 10^{8} \mathrm{~kg}$ for the polluted cloud (T1RH1_4000). This results in delayed and weaker precipitation from the polluted clouds (in Figs. 3 and 4 we present the results of the most humid profile, so this effect is less significant than in the other profiles). Such competition between opposing processes yields an optimal aerosol concentration for the total cloud mass as well as for the rain yield, with a value in between the two examples. Figures 2 and 3 show that, for the total cloud mass and peak rain (the maximal rain rate), a concentration of around $1000 \mathrm{~cm}^{-3}$ results in larger values compared with 125 and $4000 \mathrm{~cm}^{-3}$.

When the impact of aerosol on the time difference between the onset and peaks of key processes is explored further, one can see that for the more polluted clouds the time lag between the peaks in the condensation mass and the collisioncoalescence mass per unit time is longer (Fig. 5). Note that, in the extreme polluted cases, for some of the initialization profiles the collision-coalescence process is almost totally suppressed and, therefore, their information is not presented in the figure. In the cleaner cases, driven by efficient collection, the maximum collected mass per unit time appears before the maximum in the condensed mass (see the negative values of the time difference in Fig. 5) even though the condensation process obviously starts earlier.

We note that the delay in the onset of the collisioncoalescence process in the polluted clouds has two opposing effects on the updraft. The first one, as was mentioned before, delays the reduction in the integrated droplets' surface area and maintains an effective condensation process (which is originally more effective in the polluted clouds). The more efficient condensation leads to a stronger latent heat release that supports the positive buoyancy of the cloud. On the other hand, a delay in the collision-coalescence implies a delay in the droplet sedimentation and, therefore, later as the droplets' mass accumulates, the updraft is reduced due to increased drag force.

As for periphery-based processes, since stronger downdrafts, driven by the evaporation, induce stronger horizontal winds (Altaratz et al., 2008a, b), the magnitude of the horizontal winds near the cloud margins can serve as a measure of the entrainment strength. In agreement with previous studies (Xue and Feingold, 2006; Jiang et al., 2006; Small et al., 2009), the polluted clouds exhibit stronger horizontal wind
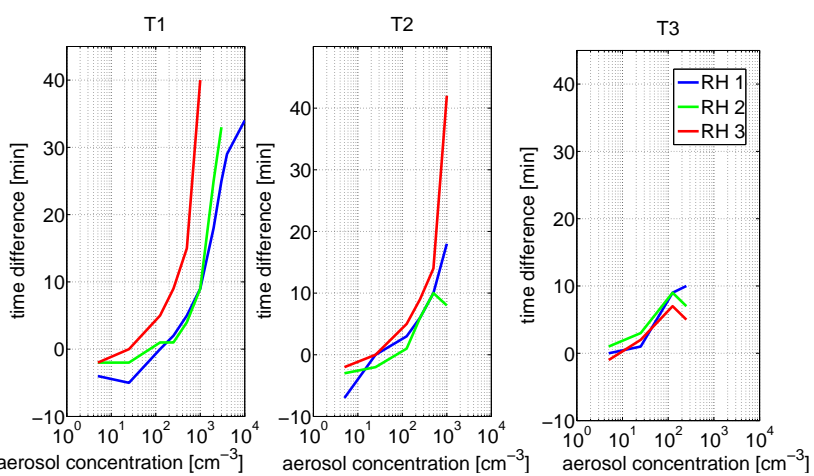

Figure 5. The time difference between the maximum collected mass per unit time and the maximum condensed mass per unit time for each simulated cloud as a function of the aerosol concentration. T1 represents a profile with an inversion layer located at $4 \mathrm{~km}, \mathrm{~T} 2$ at $3 \mathrm{~km}$, and T3 at $2 \mathrm{~km}$. RH1 represents a profile with $95 \% \mathrm{RH}$ in the cloudy layer, RH2 $90 \%$, and RH3 80\%. Each curve represents 10 simulations performed for an initialization profile (a total of nine profiles).

velocity for all profiles. For example, for the T1RH1 profiles, the mean horizontal winds averaged along the cloud margins (which were defined according to $\mathrm{RH}=100 \%$ ) were $0.31,0.41$, and $0.45 \mathrm{~m} \mathrm{~s}^{-1}$ for T1RH1_125, T1RH1_1000, and T1RH1_4000, respectively. Similarly, throughout this paper, the cloud core is defined as the part under supersaturation conditions, while the cloud periphery is the part under subsaturation (Wang et al., 2009). This definition determines the dominant processes in each of these regions in the cloud: the core is dominated by condensation and the periphery by evaporation and entrainment.

These results, obtained using an axisymmetric model with a geometry that is only an idealization and simplification of a full 3-D flow. This may affect the estimation of the entrainment strength and turbulence mixing, as was discussed in details in Benmoshe et al. (2012) (focusing on the comparison between 2-D and 3-D cloud models).

We see that, similarly to the condensation argument, the ratio of the total drops surface area to volume increases with increasing aerosol concentration (see Fig. 4), meaning that the smaller droplets evaporate more efficiently (Xue and Feingold, 2006).

The evaporation is enhanced by positive feedback because the enhanced downdrafts at the cloud's periphery further increase the mixing of outer air into the cloud. The magnitude of this effect strongly depends on the environmental humidity. As the humidity increases, the relative effect of the entrainment process decreases.

Similarly to the droplets' scale, the size of the whole cloud plays an important role in controlling the entrainment impact. Larger clouds have a smaller surface area $(A)$ to volume $(V)$ ratio $\left(\eta=A V^{-1}\right)$ and, therefore, a smaller portion of them comes in direct contact with the drier surroundings 

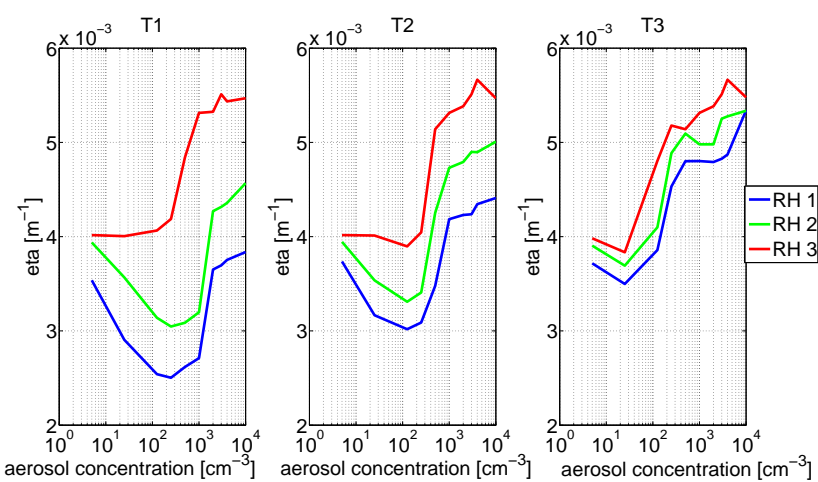

Figure 6. Minimal values of the surface area to volume ratio (eta) for each simulated cloud as a function of the aerosol concentration. $\mathrm{T} 1$ represents a profile with an inversion layer located at $4 \mathrm{~km}, \mathrm{~T} 2$ at $3 \mathrm{~km}$, and T3 at $2 \mathrm{~km}$. RH1 represents a profile with $95 \% \mathrm{RH}$ in the cloudy layer, RH2 $90 \%$, and RH3 $80 \%$. Each curve represents 10 simulations performed for an initialization profile (a total of nine profiles).

(Simpson, 1971; Stirling and Stratton, 2012). The minimal value of $\eta$ during the lifetime of each cloud for all the different simulations (Fig. 6) shows a non-monotonic response to aerosol loading which is opposite to the effect of aerosol on the total mass. For most initialization profiles the cloud that corresponds to the maximum mass has the smallest $\eta$. Moreover, the difference in $\eta$ between the different initialization profiles is also shown. As the inversion base height becomes higher or the RH outside of the cloud increases, the value of $\eta$ generally decreases. With a larger value of $\eta$, stronger periphery-based (suppression) processes can be expected.

Figure S3 in the Supplement presents the time evolution of $\eta$ for three clouds that developed under different initial atmospheric profiles (T1RH1 - blue, T2RH2 - green and T3RH3 - red) with the same aerosol loading $\left(4000 \mathrm{~cm}^{-3}\right)$. Once again we see that as the inversion base height and the RH in the cloudy layer decrease the value of $\eta$ increases.

The competing effects discussed above show that, on the one hand, more aerosols result in enhanced condensation (higher efficiency and for a longer time) and stronger latent heat release, which leads to deeper clouds with a larger water mass. On the other hand, more aerosols induce mass accumulation that enhances drag forces and stronger entrainmentdriven evaporation (suppression processes), which eventually leads to mass reduction and smaller clouds. This competition poses the existence of an optimal value $\left(N_{\mathrm{op}}\right)$ with respect to the cloud mass, which dictates a change in the sign of the trend regarding the cloud mass response to an increase in aerosol loading (Fig. 2). The value of $N_{\text {op }}$ strongly depends on the environmental conditions. As the inversion's base height increases (increasing the potential cloud depth and therefore reducing the cloud's surface area-to-volume ratio) and/or the humidity outside of the cloud increases, the entrainment impact weakens and, therefore, $N_{\text {op }}$ increases.
For similar temperature profiles, a reduced $\mathrm{RH}$ outside of the cloud (different curves in each panel in Fig. 2) would enhance the entrainment (by mixing drier environmental air into the cloud) and, therefore, $N_{\text {op }}$ would decrease. However, for profiles with a similar RH outside of the cloud, a reduction in the inversion base height would change the cloud's size and the cloud's surface area-to-volume ratio. This again changes the portion of the cloud that is influenced by the drier ambient air and strengthens the entrainment. Smaller clouds have a higher surface area-to-volume ratio and therefore the entrainment plays a more important role. This is reflected by the smaller $N_{\text {op }}$ values for the smaller clouds.

The ratio of the cloud's surface area to volume $(\eta)$ can serve as a measure of the balance between core and periphery-based processes in clouds. The core-based processes are more adiabatic in nature (since the core is less exposed to entrainment) (Wang et al., 2009) and therefore, for given temperature and humidity profiles, they are less affected by the suppressing branch of the aerosol effect (enhance evaporation and entrainment). Therefore, higher aerosol loading yields more efficient condensation (a larger droplet surface area) for a longer time (owing to the postponement in the collision-coalescence process). On the other hand, over the cloud's periphery, more aerosols enhance the evaporation and the mixing with the outer air.

This impact of aerosol loading on the magnitude and timing of the core versus the periphery-based cloud processes is reflected in the response of different cloud features. Figure 7 presents three cloud properties for each simulation as a function of the aerosol concentration (each curve represents 10 simulations of specific profiles): (1) the maximum cloud top height per simulation (defined by the height level of $0.01 \mathrm{~g} \mathrm{~kg}^{-1}$ liquid water content; top panels), (2) the maximum (over the cloud's lifetime) of the mean cloud's updraft (middle panel). As vertical velocity serves as an important factor that controls the droplets' vertical displacement, the average is weighted by the liquid water mass. The (nonweighted) maximum vertical velocity (Fig. S2 in the Supplement) shows similar results but is more sensitive to local fluctuations of the velocity field, and (3) the total amount of surface rain (bottom panels). A similar reversal trend with a clear extreme was observed for all nine profiles for all three measures. For the three cloud features shown, the optimal concentration per atmospheric profile is at a slightly higher aerosol loading compared with the $N_{\text {op }}$ value, which was defined as the optimum aerosol concentration for the maximum in the total mass. The aerosol concentration that gives the peak of the cloud features that are controlled by the cloud's core processes, like cloud top height (less affected by entrainment), corresponds to larger aerosol loading values compared to features that are more sensitive to periphery-based processes (like total cloud mass). Eventually, since all the processes are coupled, the enhancement in the periphery's effects results in a weakening of the core-based processes as well. The maximum total mass of the cloud is more sensitive 

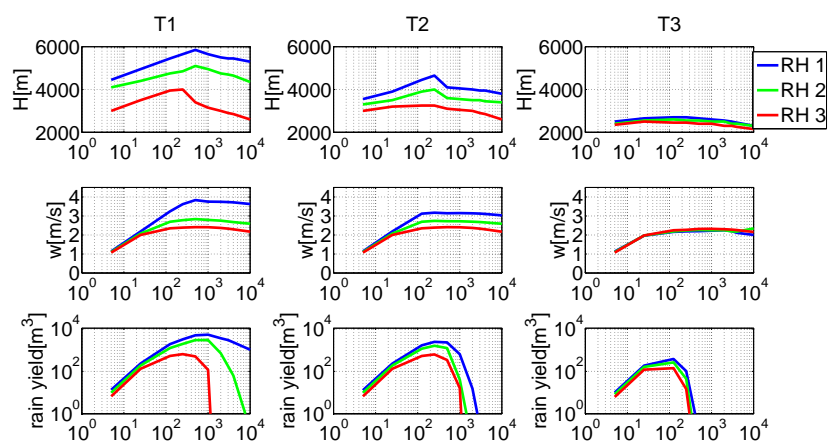

aerosol concentration $\left[\mathrm{cm}^{-3}\right]$

aerosol concentration [cm

Figure 7. The cloud's maximum top height (top panels), the maximum over time of the mean vertical velocity weighted by the mass in each grid point (middle panels) and the total surface rain yield (bottom panels) as a function of the aerosol loading, for each simulated cloud as a function of the aerosol concentration. Each curve represents 10 simulations performed for an initialization profile (a total of nine profiles).

to the cloud periphery-based processes. The cloud's maximum top height (which is located above the cloud's core) is less sensitive to these processes.

Similarly, since the mean updraft is weighted by the liquid water mass and is therefore less sensitive to aerosol effects on the lighter periphery (contain less liquid water mass), the declining branch (in the graphs in the middle panel in Fig. 7) that is controlled by the enhanced entrainment and evaporation at the clouds' periphery is less significant.

Rain is in many ways the end result of all the cloud processes; the total condensed and evaporated mass controls the cloud's total water mass together with the collisioncoalescence process that drives the formation of the rain drops.

An optimal aerosol concentration, followed by a reverse in the sign of the trend, is also shown for the rain (as can be seen in Fig. 7, bottom panel). The aerosol concentration value that corresponds to the maximal rain yield (per initialization profile) usually increases for profiles with a higher inversion base height and/or a more humid environment in the cloudy layer, and in most cases these values are higher than $N_{\text {op }}$ (in seven out of the nine initial profiles - for the other two they are equal). As a first approximation, rain is expected to scale well with the total water mass (neglecting the evaporation of rain below the cloud), this suggests similarities in the optimal aerosol concentration for total mass and rain. So why does the maximum in the surface rain yields correspond to larger optimal aerosol concentrations?

The reason is the dependency of rain on the collection efficiency. In clean clouds the collection process becomes significant early compared to polluted clouds, but the total collected mass (integrated over the cloud lifetime) does not necessarily decrease with the increase in aerosol loading. The collected mass increases with both the number concentra-

tion and the variance of the droplet size distribution. Thus, aerosols would have a contradictory effect on the total collected mass. At low values of aerosol concentrations, as the aerosol loading increases, a few big lucky drops (Kostinski and Shaw, 2005) that initiate the rain can collect more small drops and consequently produce more rain yield and larger rain drops (Altaratz et al., 2008b). The mean rain drop radius below the cloud base can serve as evidence for this process (see the results produced by the same model in the paper by Altaratz et al., 2008b). For example, in our results, for the profile T1RH2 the cloud forming in aerosol loading of $125 \mathrm{~cm}^{-3}$ has a maximum (over time) of mean radius below cloud base (at $H=750 \mathrm{~m}$ ) of $0.77 \mathrm{~mm}$ (at $t=56 \mathrm{~min}$ ) while the cloud with aerosol loading of $2000 \mathrm{~cm}^{-3}$ has a maximum mean radius at the same height of $1.21 \mathrm{~mm}$ (at $t=81 \mathrm{~min}$ ).

This trend continues until the effect of the smaller variance of the droplet size distribution (with increasing aerosol loading) becomes more important and then there are less lucky drops. The aerosol concentration that corresponds to the maximum total collection efficiency for a given profile is slightly higher than $N_{\text {op }}$.

Finally, it should be noted that the differences between the cases of the small warm clouds (profile T3) are smaller (compared to the deeper clouds) and, as expected, have low values of optimal aerosol concentrations. For all of those small clouds their top is above the inversion and, thus, most of the evaporation takes place in a similar very dry environment $\left(\mathrm{RH}=30 \%\right.$ ) and $N_{\text {op }}$ values were shown to be $\sim 25 \mathrm{~cm}^{-3}$ for the T3 cases (Fig. 2). This suggests that under our current atmospheric conditions, apart from the extremely pristine places, the local aerosol concentrations are larger than the optimal value, locating the clouds already on the descending branch. Similarly, the clouds' top height, for the T3 cases, shows relatively low sensitivity to aerosol loading, with optimal concentrations of $\sim 100 \mathrm{~cm}^{-3}$ (Fig. 7).

These results may bridge the ongoing gap between observations and modeling studies of aerosol effects on warm convective clouds. Differences in the studied clouds' dimensions might be the source of some of the discrepancies. Many of the numerical studies of warm convective clouds focused on trade-like cumulus clouds (Jiang et al., 2006, 2009, 2010; Xue and Feingold, 2006; Xue et al., 2008; Koren et al., 2009; Seigel, 2014) where the characteristic cloud size is about $1 \mathrm{~km}$. However, due to limitations in the spatial resolution, Earth-observing satellite instruments (such as MODIS) are biased toward much larger clouds (Kaufman et al., 2005; Yuan et al., 2011; Koren et al., 2014). Therefore, our results suggest that warm cloud simulations will more likely capture the descending branch of the trend, whereas satellite data will be biased toward larger clouds that are characterized by higher optimal aerosol levels and therefore will more likely capture the ascending branch. 


\section{Summary}

Cloud properties are controlled by both the thermodynamic conditions and by the aerosol properties. Here our aim was to study the interplay between these main players for warm clouds. Although using a single cloud model that cannot capture processes in a cloud-field scale, we found a very rich interplay between key warm processes that shed new light on previous results found by numerical models and observations. More specifically, we showed that a reversal in the trend sign takes place when initially a cloud mass increases with aerosol loading up to a turning point, defined here as the optimal concentration, $N_{\mathrm{op}}$, followed by a decrease in the maximal cloud mass. This reversal in trend sign was shown to be applicable to other cloud properties such as the cloud's top height, updraft, and rain; however, the optimal concentration is not the same as the one for the total mass. The dependency of $N_{\text {op }}$ on the thermodynamic conditions was examined (over a large range of environmental conditions including, for example, a very humid environment that weakens the entrainment role). Specifically, we showed that more unstable temperature profiles and higher relative humidity enable larger $N_{\text {op }}$ values; namely, clouds are aerosol-limited up to higher aerosol concentrations.

The existence of an optimal concentration results from two competing effects. On the one hand, more aerosols provide a larger droplet surface area for condensation and delay the onset of collection processes and, therefore, drive stronger latent heat release and more condensed mass to be formed and to be pushed upward. On the other hand, more aerosols result in stronger entrainment and a stronger drag force (driven by the larger mass) that suppress the cloud's development. In that respect, we noted that invigoration effects are more associated with cloud core-based processes where the cloud is closer to being adiabatic and the likelihood of larger supersaturation is higher. However, cloud suppression effects are likely to occur more in the cloud's peripheral regions where unsaturated, drier air enters the cloud. Optimal aerosol concentrations were discussed before in the context of precipitation susceptibility (Jiang et al., 2010) and sensitivity to wind shear conditions for deep convective clouds (Fan et al., 2009). In this work the focus is on warm convective clouds with a detailed description of the competition between all the processes involved under different environmental conditions.

Such opposite associations with respect to the location within the cloud imply that the total cloud surface area-tovolume ratio (defined here as $\eta$ ) is an informative parameter. For larger $\eta$ values, a stronger effect of the periphery-based processes is expected to influence the cloud's fate. Therefore, for profiles that support only small convective cloud formations (lower inversion and lower environmental RH), $\eta$ would have larger values and therefore smaller $N_{\text {op }}$ concentrations. This suggests that for most cases in nature (where the atmospheric conditions are between slightly and strongly polluted) small clouds would be beyond their $N_{\text {op }}$ values, on the descending branch of the trend (suppression effect). On the other hand, profiles that support deeper convection (high inversion and high environmental $\mathrm{RH}$ ) would produce deeper clouds with smaller $\eta$ values and therefore larger $N_{\mathrm{op}}$ concentrations. This can be translated into a higher likelihood of finding in nature deeper clouds that are aerosol-limited and, consequently, on the ascending (invigoration) branch. Such a view bridges the gap between conflicting reports from numerical model studies that tend to simulate small trade-like clouds and mostly report on suppression by aerosols and observations that, owing to pixel resolution, are biased toward larger clouds and mostly report on invigoration.

In this paper we discuss the importance of both the timing and the magnitude of processes; however, in order to reduce the complexity, we discussed the time evolution of the clouds only briefly. We compared the onset or maximal values of processes instead of the entire evolution. Such a view captures well and in a condensed way the overall results but not the whole story. For example, it is obvious that the increase in condensation efficiency by aerosols will reach a saturation stage in which the characteristic time for consuming the available water vapors is much smaller compared with the advection timescale (Pinsky et al., 2013). We could see this in our results when we compared the condensation curves of the 1000 and $4000 \mathrm{~cm}^{-3}$ cases (Fig. 3). The condensation curve is similar and most of the effect is driven by the delay in the collection processes. In many ways the core versus the periphery-based processes view can be linked to the time evolution of a cloud. The early stages of the cloud are more adiabatic, whereas the dissipation stage of the cloud, by definition, is controlled more by periphery-based processes. Therefore, we can conclude that even during a single cloud evolution more aerosols can be translated into invigoration in the early stages and to suppression in the later ones. The question addressed in this paper is what factor dominates and what the overall result is.

Similarly, throughout the paper we discuss drag forces as a factor that opposes invigoration. This again is accurate from the end-results viewpoint. When it is examined from the time perspective of one given cloud, enhanced drag forces can be viewed not only as opposing, but also as a result of invigoration, i.e., "enjoy now and pay later". Drag forces are scaled with mass; therefore, an invigorated cloud that "enjoys" the benefits of more aerosols during the early stages (when the profile is unstable enough and the RH is high and therefore $N_{\text {op }}$ is large) will "pay" at later stages when it carries a large accumulated mass that enhances the drag force. Thus, again, the timing perspective is extremely important and provides a much richer view of the problem.

There is a need to further study the synergism between the single-cloud-scale processes (as described in this work) and the processes that act on the field scale. The overall aerosol effect on warm cloud fields would be a result of both types of processes. 


\section{The Supplement related to this article is available online at doi:10.5194/acp-15-2749-2015-supplement.}

Acknowledgements. The research leading to these results received funding from the European Research Council under the European Union's Seventh Framework Programme (FP7/2007-2013) /ERC Grant agreement no. 306965.

Edited by: C. Hoose

\section{References}

Albrecht, B. A.: Aerosols, cloud microphysics, and fractional cloudiness, Science, 245, 1227-1230, 1989.

Altaratz, O., Koren, I., and Reisin, T.: Humidity impact on the aerosol effect in warm cumulus clouds, Geophys. Res. Lett., 35, L17804, doi:10.1029/2008GL034178, 2008a.

Altaratz, O., Koren, I., Reisin, T., Kostinski, A., Feingold, G., Levin, Z., and Yin, Y.: Aerosols' influence on the interplay between condensation, evaporation and rain in warm cumulus cloud, Atmos. Chem. Phys., 8, 15-24, doi:10.5194/acp-8-15-2008, 2008 b.

Altaratz, O., Koren, I., Remer, L., and Hirsch, E.: Review: Cloud invigoration by aerosols - Coupling between microphysics and dynamics, Atmos. Res., 140, 38-60, 2014.

Andreae, M. O., Rosenfeld, D., Artaxo, P., Costa, A. A., Frank, G. P., Longo, K. M., and Silva-Dias, M. A. F.: Smoking rain clouds over the Amazon, Science, 303, 1337-1342, doi:10.1126/science.1092779, 2004.

Baker, M. B. and Peter, T.: Small-scale cloud processes and climate, Nature, 451, 299-300, doi:10.1038/nature06594, 2008.

Benmoshe, N., Pinsky, M., Pokrovsky, A., and Khain, A.: Turbulent effects on the microphysics and initiation of warm rain in deep convective clouds: 2-D simulations by a spectral mixedphase microphysics cloud model, J. Geophys. Res.-Atmos., 117, D06220, doi:10.1029/2011jd016603, 2012.

Boucher, O., Randall, D., Artaxo, P., Bretherton, C., Feingold, G., Forster, P., Kerminen, V., Kondo, Y., Liao, H., and Lohmann, U.: Clouds and aerosols, Clim. Change, 571-657, 2013.

Costantino, L. and Bréon, F.-M.: Aerosol indirect effect on warm clouds over South-East Atlantic, from co-located MODIS and CALIPSO observations, Atmos. Chem. Phys., 13, 69-88, doi:10.5194/acp-13-69-2013, 2013.

Dey, S., Di Girolamo, L., Zhao, G., Jones, A. L., and McFarquhar, G. M.: Satellite-observed relationships between aerosol and trade-wind cumulus cloud properties over the Indian Ocean, Geophys. Res. Lett., 38, L01804. doi:10.1029/2010GL045588, 2011.

Fan, J., Yuan, T., Comstock, J. M., Ghan, S., Khain, A., Leung, L. R., Li, Z., Martins, V. J., and Ovchinnikov, M.: Dominant role by vertical wind shear in regulating aerosol effects on deep convective clouds, J. Geophys. Res.-Atmos., 114, D22206, doi:10.1029/2009jd012352, 2009.

Fan, J., Leung, L. R., Rosenfeld, D., Chen, Q., Li, Z., Zhang, J., and Yan, H.: Microphysical effects determine macrophysical response for aerosol impacts on deep convective clouds, P. Natl. Acad. Sci., 110, E4581-E4590, 2013.
Feingold, G., Cotton, W. R., Kreidenweis, S. M., and Davis, J. T.: The impact of giant cloud condensation nuclei on drizzle formation in stratocumulus: Implications for cloud radiative properties, J. Atmos. Sci., 56, 4100-4117, doi:10.1175/15200469(1999)056<4100:tiogcc>2.0.CO;2, 1999.

Fitzgerald, J. and Spyers-Duran, P.: Changes in cloud nucleus concentration and cloud droplet size distribution associated with pollution from St. Louis, J. Appl. Meteorol., 12, 511-516, 1973.

Forster, P., Ramaswamy, V., Artaxo, P., Berntsen, T., Betts, R., Fahey, D. W., Haywood, J., Lean, J., Lowe, D. C., Myhre, G., Nganga, J., Prinn, R., Raga, G., Schulz, M., and Dorland, R. V.: Changes in Atmospheric Constituents and in Radiative Forcing., in: Climate Change 2007: The Physical Science Basis. Contribution of Working Group I to the Fourth Assessment Report of the Intergovernmental Panel on Climate Change, edited by: Solomon, S., Qin, D., Manning, M., Chen, Z., Marquis, M., Averyt, K. B., Tignor, M., and Miller, H. L., 129-234, Cambridge University Press, Cambridge, UK and New York, NY, USA, 2007.

Freud, E. and Rosenfeld, D.: Linear relation between convective cloud drop number concentration and depth for rain initiation, J. Geophys. Res. Atmos., 117, D02207, doi:10.1029/2011JD016457, 2012.

Garstang, M. and Betts, A. K.: A review of the tropical boundary layer and cumulus convection: Structure, parameterization, and modeling, B. Am. Meteor. Soc., 55, 1195-1205, 1974.

Gunn, R. and Phillips, B.: An experimental investigation of the effect of air pollution on the initiation of rain, J. Meteorol., 14, 272-280, 1957.

Jaenicke, R.: Aerosol physics and chemistry, Landolt-Börnstein Neue Serie 4b, 391-457, 1988.

Jiang, H., Xue, H., Teller, A., Feingold, G., and Levin, Z.: Aerosol effects on the lifetime of shallow cumulus, Geophys. Res. Lett., 33, L14806, doi:10.1029/2006GL026024, 2006.

Jiang, H., Feingold, G., and Koren, I.: Effect of aerosol on trade cumulus cloud morphology, J. Geophys. Res.-Atmos., 114, D11209, doi:10.1029/2009JD011750, 2009.

Jiang, H., Feingold, G., and Sorooshian, A.: Effect of aerosol on the susceptibility and efficiency of precipitation in warm trade cumulus clouds, J. Atmos. Sci., 67, 3525-3540, 2010.

Jiang, H. L. and Feingold, G.: Effect of aerosol on warm convective clouds: Aerosol-cloud-surface flux feedbacks in a new coupled large eddy model, J. Geophys. Res.-Atmos., 111, D01202, doi:10.1029/2005JD006138, 2006.

Kaufman, Y. J., Koren, I., Remer, L. A., Rosenfeld, D., and Rudich, Y.: The effect of smoke, dust, and pollution aerosol on shallow cloud development over the Atlantic Ocean, P. Natl. Acad. Sci. USA, 102, 11207-11212, doi:10.1073/pnas.0505191102, 2005.

Khain, A., Rosenfeld, D., and Pokrovsky, A.: Aerosol impact on the dynamics and microphysics of deep convective clouds, Q. J. Roy. Meteorol. Soc., 131, 2639-2663, doi:10.1256/qj.04.62, 2005.

Khain, A. P.: Notes on state-of-the-art investigations of aerosol effects on precipitation: a critical review, Environ. Res. Lett., 4, 015004, doi:10.1088/1748-9326/4/1/015004, 2009.

Khain, A. P., BenMoshe, N., and Pokrovsky, A.: Factors determining the impact of aerosols on surface precipitation from clouds: An attempt at classification, J. Atmos. Sci., 65, 1721-1748, doi:10.1175/2007jas2515.1, 2008. 
Koren, I., Kaufman, Y. J., Rosenfeld, D., Remer, L. A., and Rudich, Y.: Aerosol invigoration and restructuring of Atlantic convective clouds, Geophys. Res. Lett., 32, L14828, doi:10.1029/2005g1023187, 2005.

Koren, I., Feingold, G., Jiang, H., and Altaratz, O.: Aerosol effects on the inter-cloud region of a small cumulus cloud field, Geophys. Res. Lett., 36, L14805, doi:10.1029/2009GL037424, 2009.

Koren, I., Altaratz, O., Remer, L. A., Feingold, G., Martins, J. V., and Heiblum, R. H.: Aerosol-induced intensification of rain from the tropics to the mid-latitudes, Nature Geosci., 2012.

Koren, I., Dagan, G., and Altaratz, O.: From aerosol-limited to invigoration of warm convective clouds, science, 344, 1143-1146, 2014.

Kostinski, A. B. and Shaw, R. A.: Fluctuations and luck in droplet growth by coalescence, B. Am. Meteor. Soc., 86, 235-244, 2005.

Lee, S. S., Donner, L. J., Phillips, V. T. J., and Ming, Y.: The dependence of aerosol effects on clouds and precipitation on cloud-system organization, shear and stability, J. Geophys. Res.Atmos., 113, D16202, doi:10.1029/2007jd009224, 2008.

Lee, S. S., Kim, B.-G., Lee, C., Yum, S. S., and Posselt, D.: Effect of aerosol pollution on clouds and its dependence on precipitation intensity, Clim. Dynam., 42, 557-577, 2014.

Levin, Z. and Cotton, W. R.: Aerosol pollution impact on precipitation: A scientific review, Springer, 382 pp., 2009.

Li, Z., Niu, F., Fan, J., Liu, Y., Rosenfeld, D., and Ding, Y.: Long-term impacts of aerosols on the vertical development of clouds and precipitation, Nature Geosci., 4, 888-894, doi:10.1038/ngeo1313, 2011.

Low, T. B. and List, R.: Collision, coalescence and breakup of raindrops. Part I: Experimentally established coalescence efficiencies and fragment size distributions in breakup, J. Atmos. Sci., 39, 1591-1606, 1982.

McTaggart-Cowan, J. D. and List, R.: Collision and breakup of water drops at terminal velocity, J. Atmos. Sci., 32, 1401-1411, 1975.

Pinsky, M., Mazin, I., Korolev, A., and Khain, A.: Supersaturation and diffusional droplet growth in liquid clouds, J. Atmos. Sci., 70, 2778-2793, 2013.

Pruppacher, H. R. and Klett, J. D.: Microphysics of clouds and precipitation, Microphysics of clouds and precipitation, D. Reidel, xvi, 706 pp., 1978.

Reisin, T., Levin, Z., and Tzivion, S.: Rain Production in Convective Clouds As Simulated in an Axisymmetric Model with Detailed Microphysics. Part I: Description of the Model, J. Atmos. Sci., 53, 497-519, doi:10.1175/15200469(1996)053<0497:RPICCA>2.0.CO;2, 1996.

Reutter, P., Su, H., Trentmann, J., Simmel, M., Rose, D., Gunthe, S. S., Wernli, H., Andreae, M. O., and Pöschl, U.: Aerosol- and updraft-limited regimes of cloud droplet formation: influence of particle number, size and hygroscopicity on the activation of cloud condensation nuclei (CCN), Atmos. Chem. Phys., 9, 70677080, doi:10.5194/acp-9-7067-2009, 2009.

Rogers, R. R. and Yau, M. K.: A short course in cloud physics, vol. 113, International Series in Natural Philosophy, ButterworthHeinemann, third edition, 1989.

Rosenfeld, D., Lohmann, U., Raga, G. B., O’Dowd, C. D., Kulmala, M., Fuzzi, S., Reissell, A., and Andreae, M. O.: Flood or drought: How do aerosols affect precipitation?, Science, 321, 1309-1313, doi:10.1126/science.1160606, 2008.
Rosenfeld, D., Wood, R., Donner, L. J., and Sherwood, S. C.: Aerosol cloud-mediated radiative forcing: highly uncertain and opposite effects from shallow and deep clouds, in: Climate Science for Serving Society, Springer, 105-149, 2013.

Seifert, A. and Beheng, K. D.: A two-moment cloud microphysics parameterization for mixed-phase clouds. Part 2: Maritime vs. continental deep convective storms, Meteorol. Atmos. Phys., 92, 67-82, doi:10.1007/s00703-005-0113-3, 2006.

Seifert, A. and Heus, T.: Large-eddy simulation of organized precipitating trade wind cumulus clouds, Atmos. Chem. Phys., 13, 5631-5645, doi:10.5194/acp-13-5631-2013, 2013.

Seigel, R. B.: Shallow Cumulus Mixing and Subcloud Layer Responses to Variations in Aerosol Loading, J. Atmos. Sci., 71, 2581-2603, 2014.

Seiki, T. and Nakajima, T.: Aerosol effects of the condensation process on a convective cloud simulation, J. Atmos. Sci., 71, 833853, 2014.

Simpson, J.: On cumulus entrainment and one-dimensional models, J. Atmos. Sci., 28, 449-455, 1971.

Small, J. D., Chuang, P. Y., Feingold, G., and Jiang, H.: Can aerosol decrease cloud lifetime?, Geophys. Res. Lett., 36, L16806, doi:10.1029/2009GL038888, 2009.

Squires, P.: The microstructure and colloidal stability of warm clouds, Tellus, 10, 262-271, 1958.

Squires, P. and Twomey, S.: The relation between cloud droplet spectra and the spectrum of cloud nuclei, Geophys. Monogr. Ser., 5, 211-219, 1960.

Stirling, A. and Stratton, R.: Entrainment processes in the diurnal cycle of deep convection over land, Q. J. Roy. Meteorol. Soc., 138, 1135-1149, 2012.

Tao, W.-K., Chen, J.-P., Li, Z., Wang, C., and Zhang, C.: Impact of aerosols on convective clouds and precipitation, Reviews of Geophysics, 50, RG2001, doi:10.1029/2011RG000369, 2012.

Twomey, S.: The influence of pollution on the shortwave albedo of clouds, J. Atmos. Sci., 34, 1149-1152, 1977.

Tzivion, S., Feingold, G., and Levin, Z.: An efficient numerical solution to the stochastic collection equation, J. Atmos. Sci., 44, 3139-3149, 1987.

Tzivion, S., Reisin, T., and Levin, Z.: Numerical simulation of hygroscopic seeding in a convective cloud, J. Appl. Meteorol., 33, 252-267, 1994.

Wang, Y., Geerts, B., and French, J.: Dynamics of the cumulus cloud margin: An observational study, J. Atmos. Sci., 66, 36603677, 2009.

Warner, J.: A reduction in rainfall associated with smoke from sugar-cane fires-An inadvertent weather modification?, J. Appl. Meteorol., 7, 247-251, 1968.

Warner, J. and Twomey, S.: The production of cloud nuclei by cane fires and the effect on cloud droplet concentration, J. Atmos. Sci., 24, 704-706, 1967.

Wilson, C. T. R.: Condensation of Water Vapour in the Presence of Dust-Free Air and other Gases, Proc. Roy. Soc. Lnd., 61, 240242, 1897.

Xue, H. and Feingold, G.: Large-eddy simulations of trade wind cumuli: Investigation of aerosol indirect effects, J. Atmos. Sci., 63, 1605-1622, 2006.

Xue, H., Feingold, G., and Stevens, B.: Aerosol effects on clouds, precipitation, and the organization of shallow cumulus convec- 
tion, J. Atmos. Sci., 65, 392-406, doi:10.1175/2007jas2428.1, 2008.

Yin, Y., Levin, Z., Reisin, T. G., and Tzivion, S.: The effects of giant cloud condensation nuclei on the development of precipitation in convective clouds - a numerical study, Atmos. Res., 53, 91-116, 2000 .
Yuan, T., Remer, L. A., and Yu, H.: Microphysical, macrophysical and radiative signatures of volcanic aerosols in trade wind cumulus observed by the A-Train, Atmos. Chem. Phys., 11, 71197132, doi:10.5194/acp-11-7119-2011, 2011. 